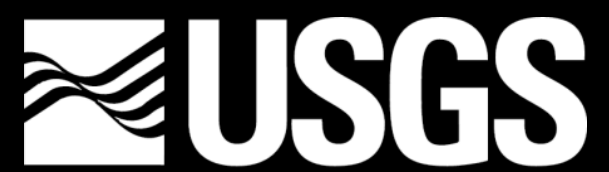

science for a changing world

\title{
Is Erosion by Lava Important on Mars?
}

Laszlo Keszthelyi (Kestay), Colin Dundas, Windy Jaeger 


\section{Outline}

- Is erosion by lava even possible?

- If so, are the primary physics of aqueous and lava floods different?

- If not, how are we going to tell their channels apart?

- Consilience: geologic context, transition zones, etc. 


\section{Erosion by lava happens on Mercury}
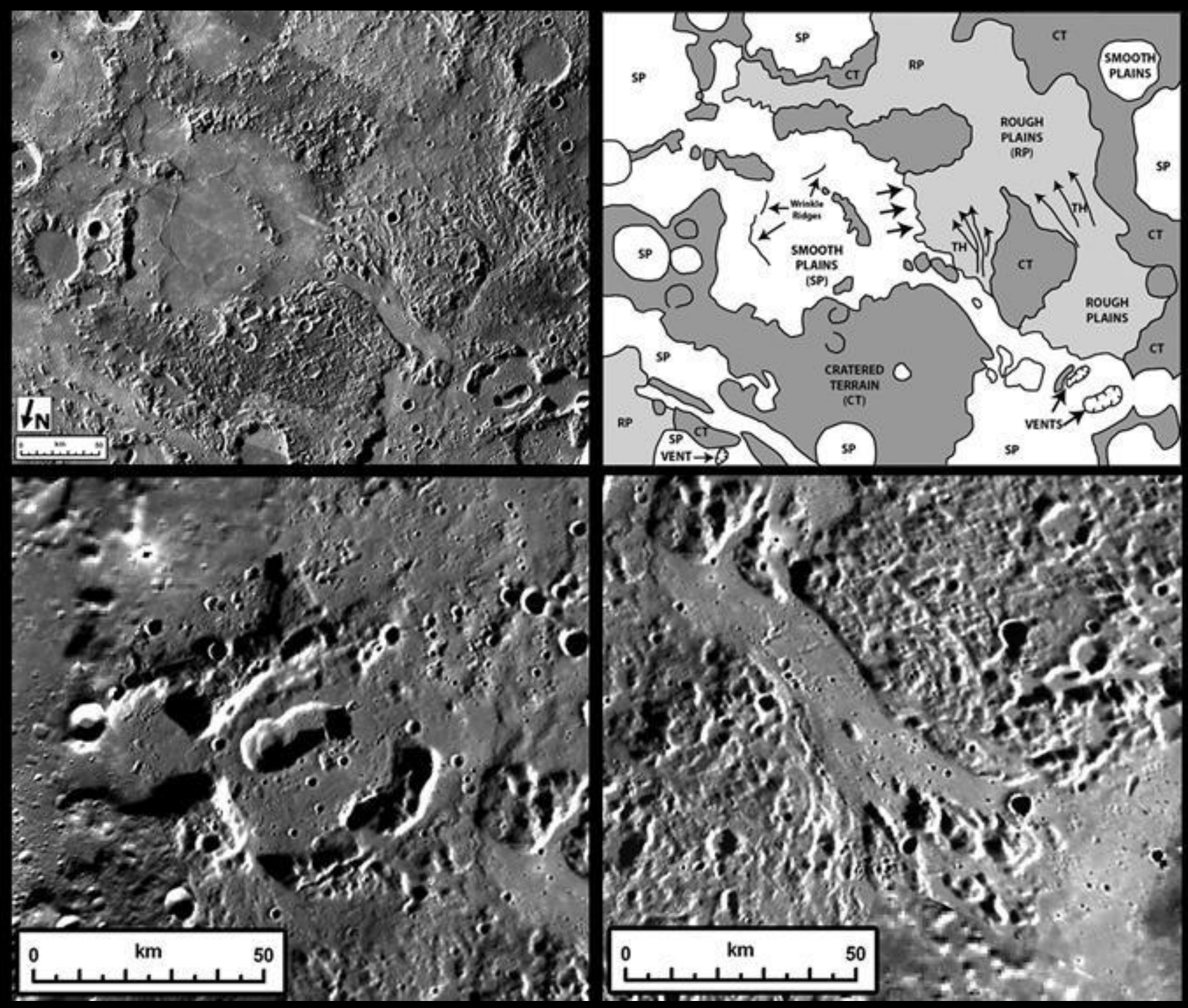


\section{Erosion by lava happens on Venus}

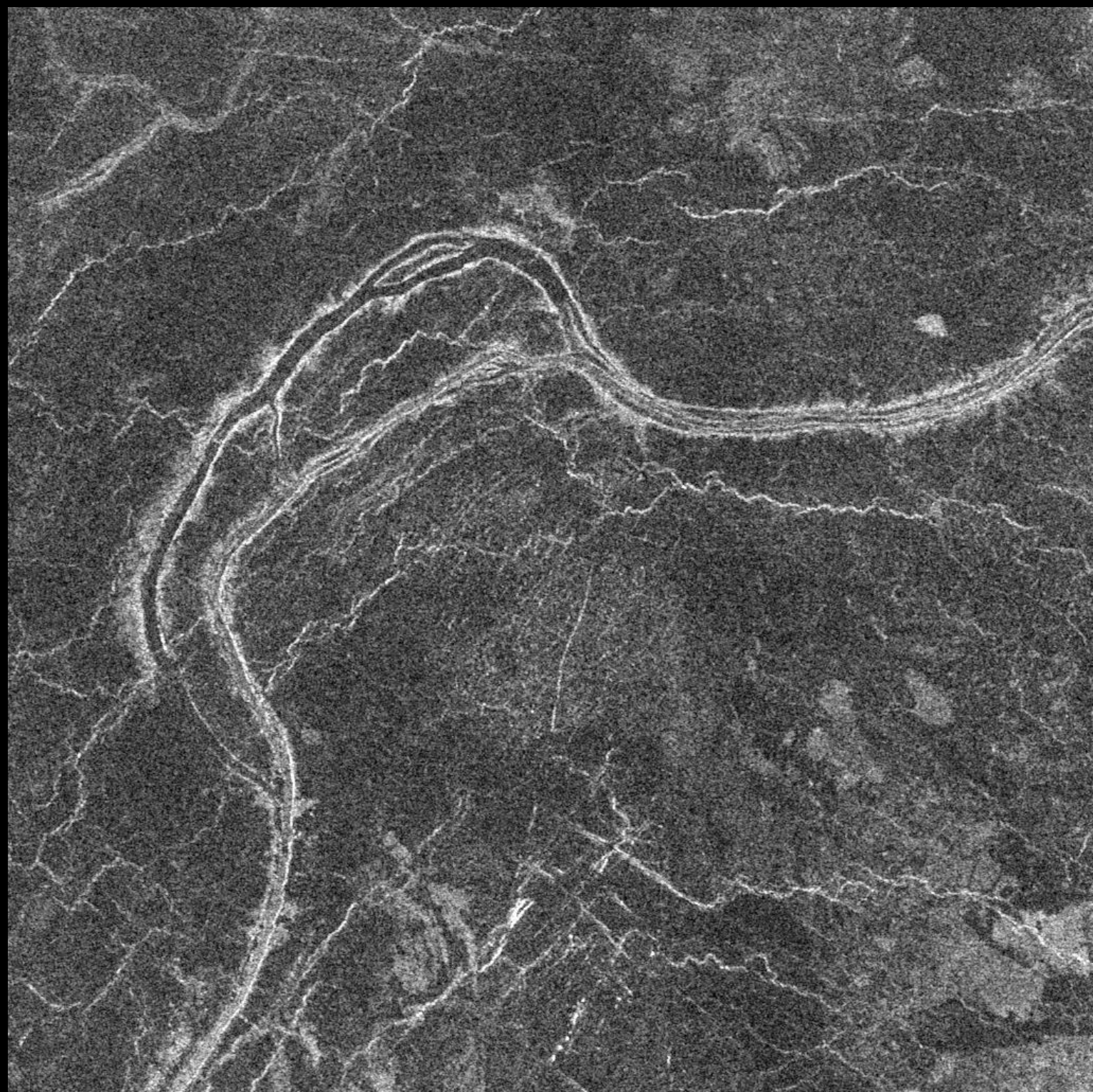




\section{Erosion by lava on the Moon}

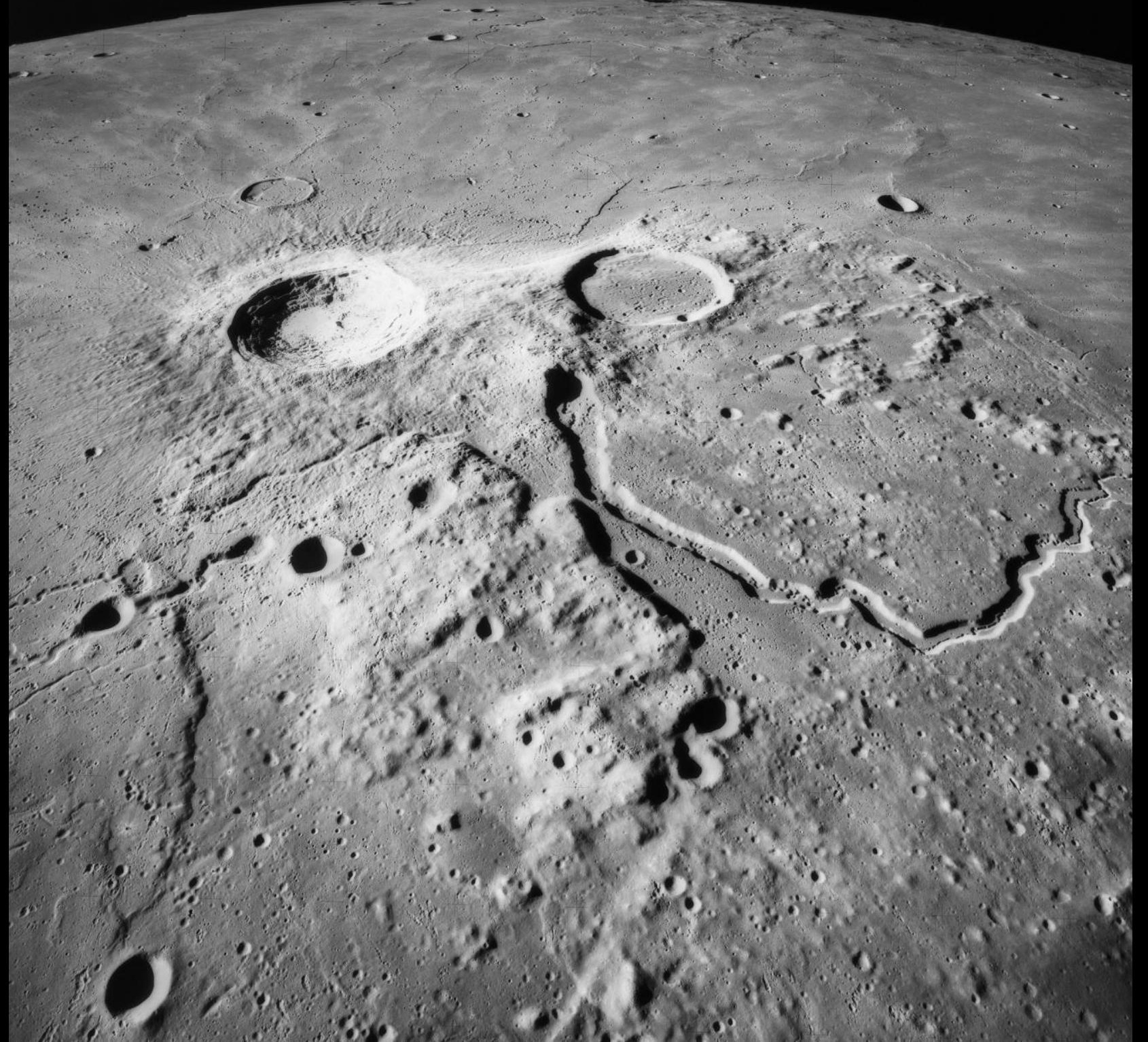




\section{Erosion by lava on the Earth}

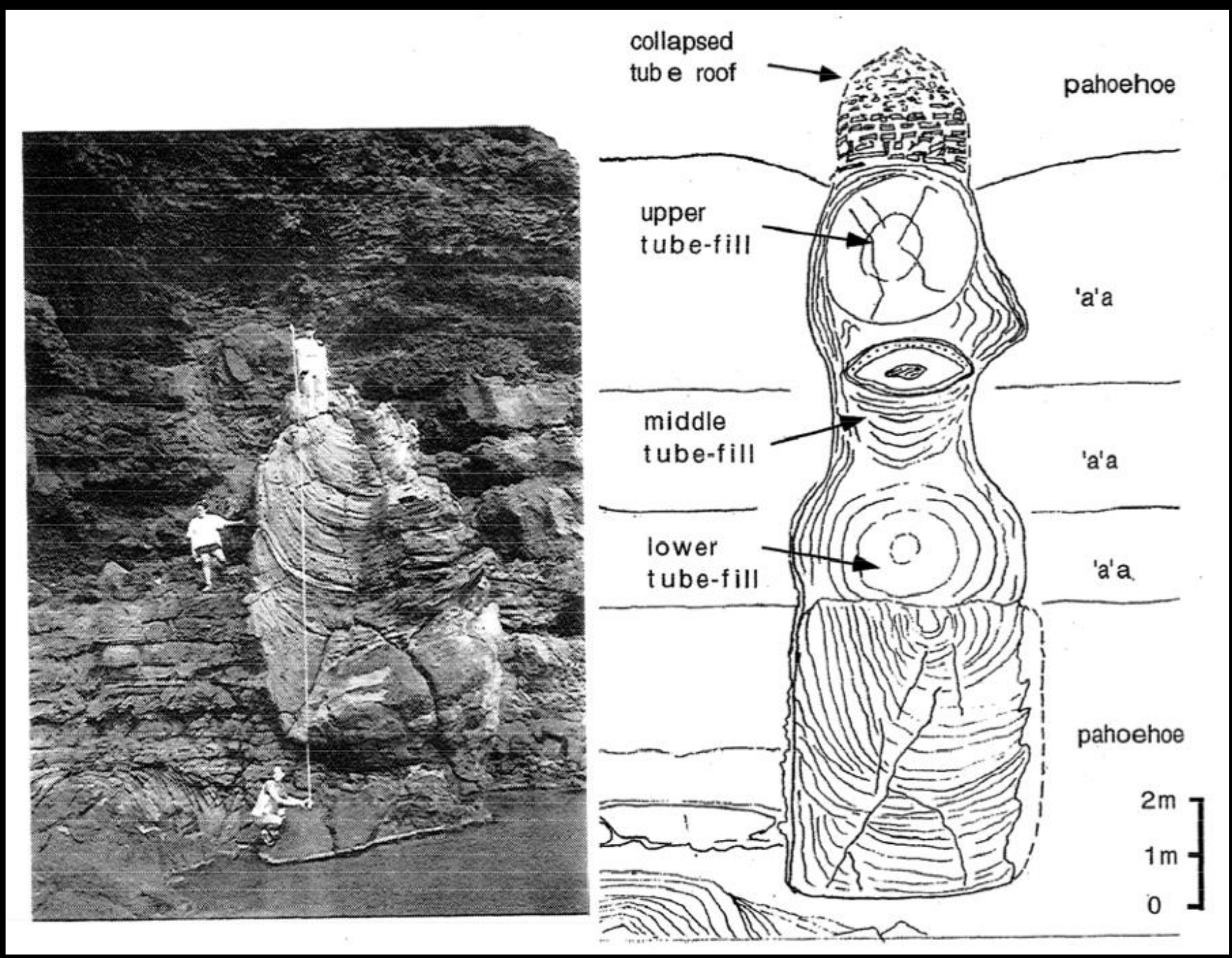




\section{But on Mars it is controversial}

\section{There is a real bias to call upon water...}

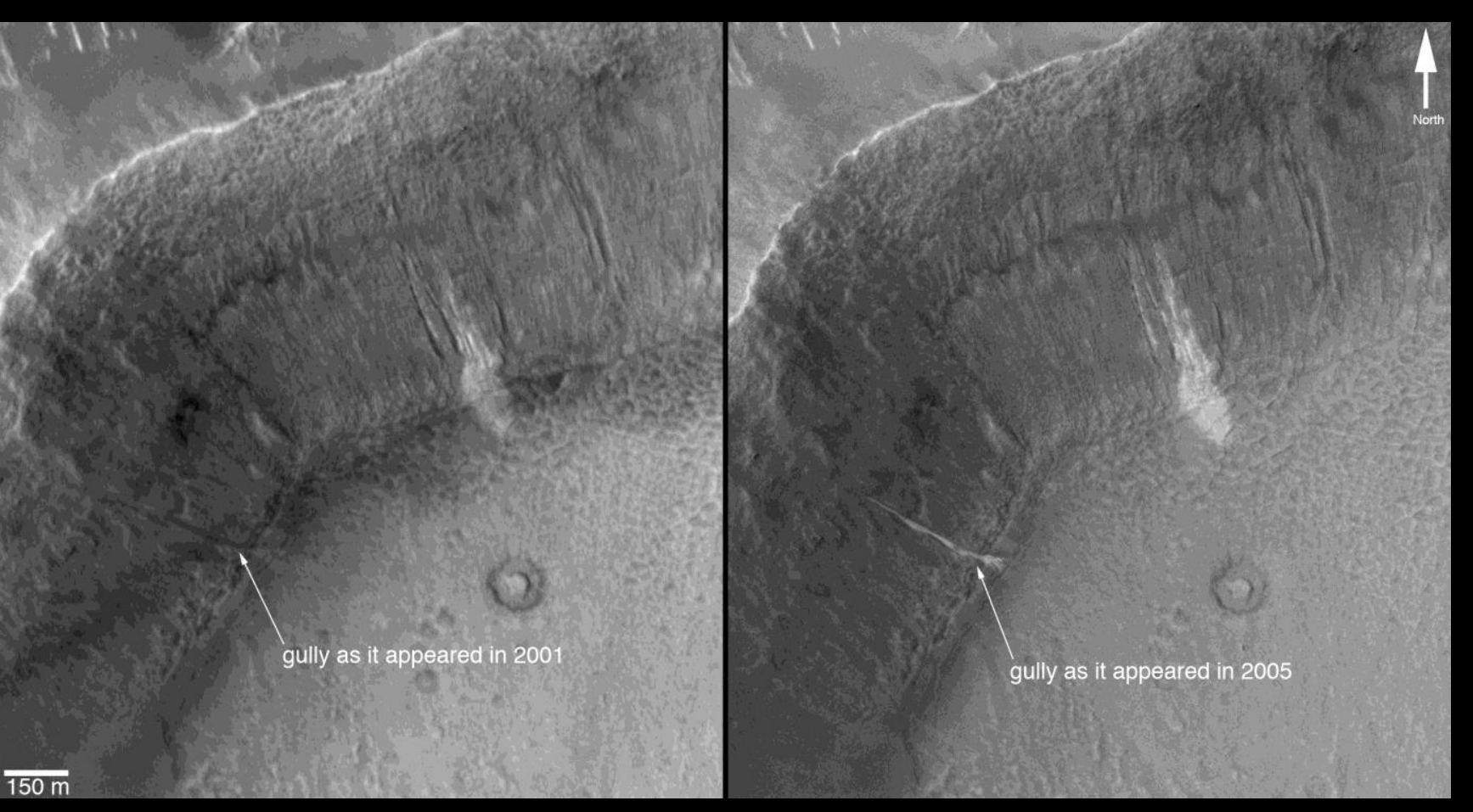

\#USGS

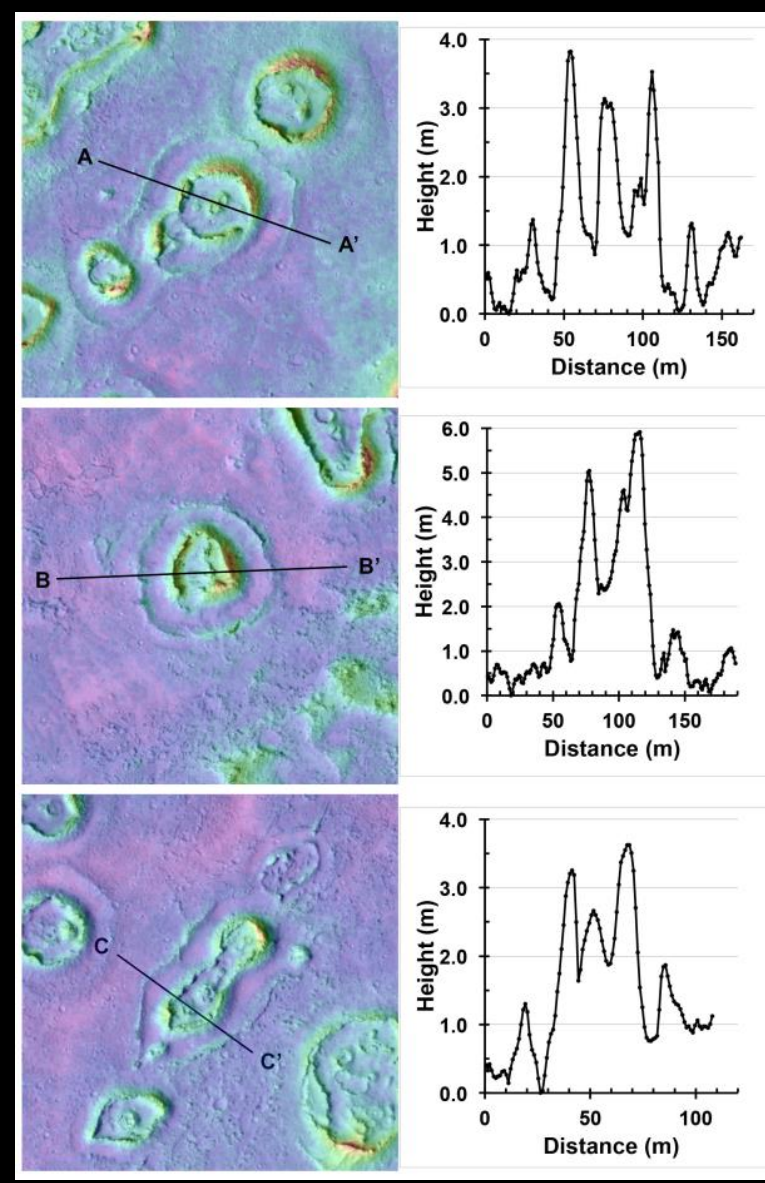




\section{Aqueous or Volcanic?}

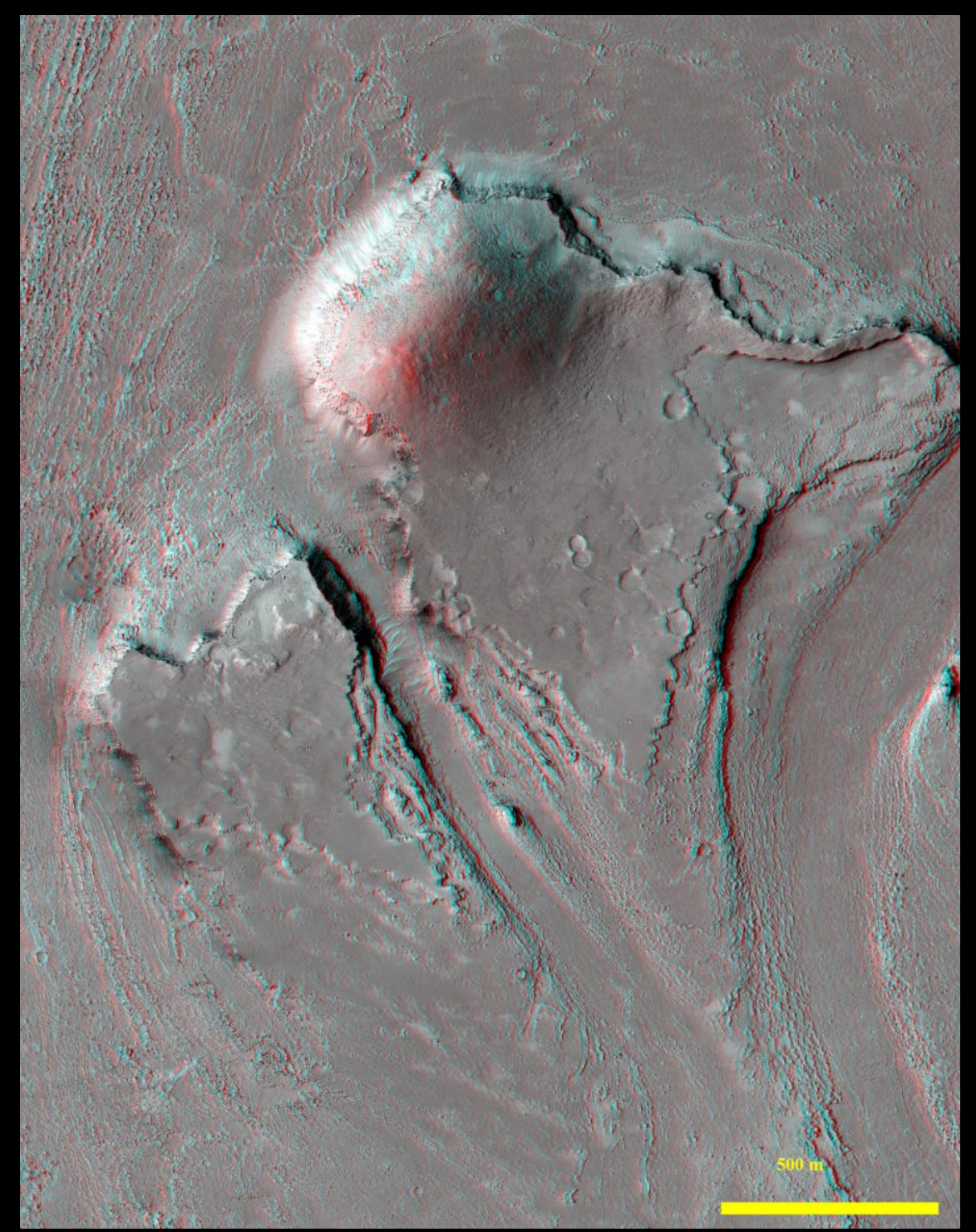




\section{Clearly Aqueous}


Clearly Volcanic

‡USGS 


\section{How to we distinguish fluvial and volcanic channels on Mars?}

- Much harder to differentiate channels formed by turbulent floods

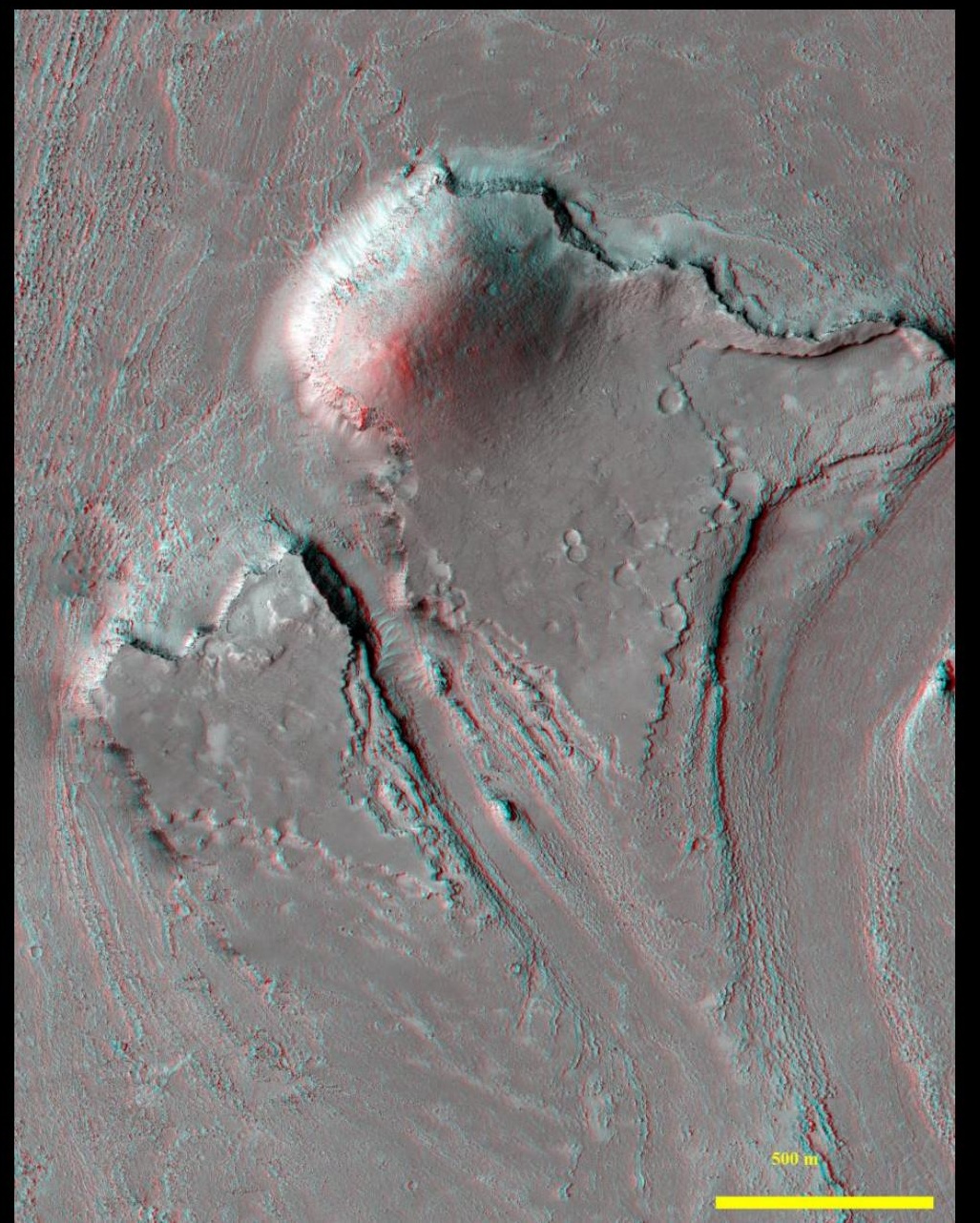




\section{Physics of turbulent lava flows}

- Much harder to differentiate channels formed by turbulent floods

- In turbulence, Re ( $\rho \mathrm{vL} / \eta)$ is what matters

- It does take a greater $L$ for lava to go turbulent

- For a given $L$, lava will have a lower Re

- Recent studies suggest erosivity controlled by Shields Number

$$
\tau^{*}=\tau /(\Delta \rho g D)
$$




\section{Physics of turbulent lava flows}
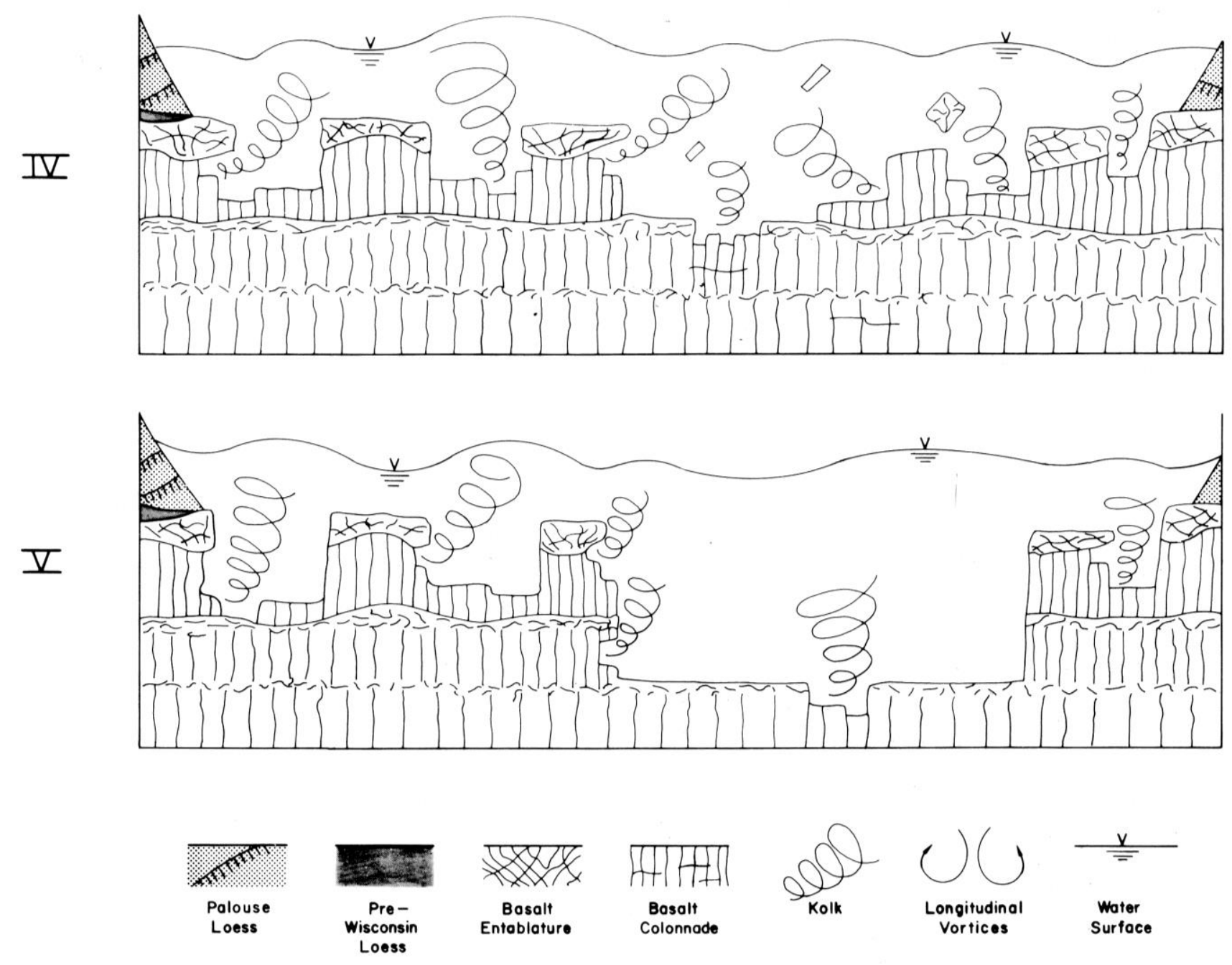


\section{What about thermal erosion?}

- Melting the substrate takes time - rate limited by conducting heat into cold ground

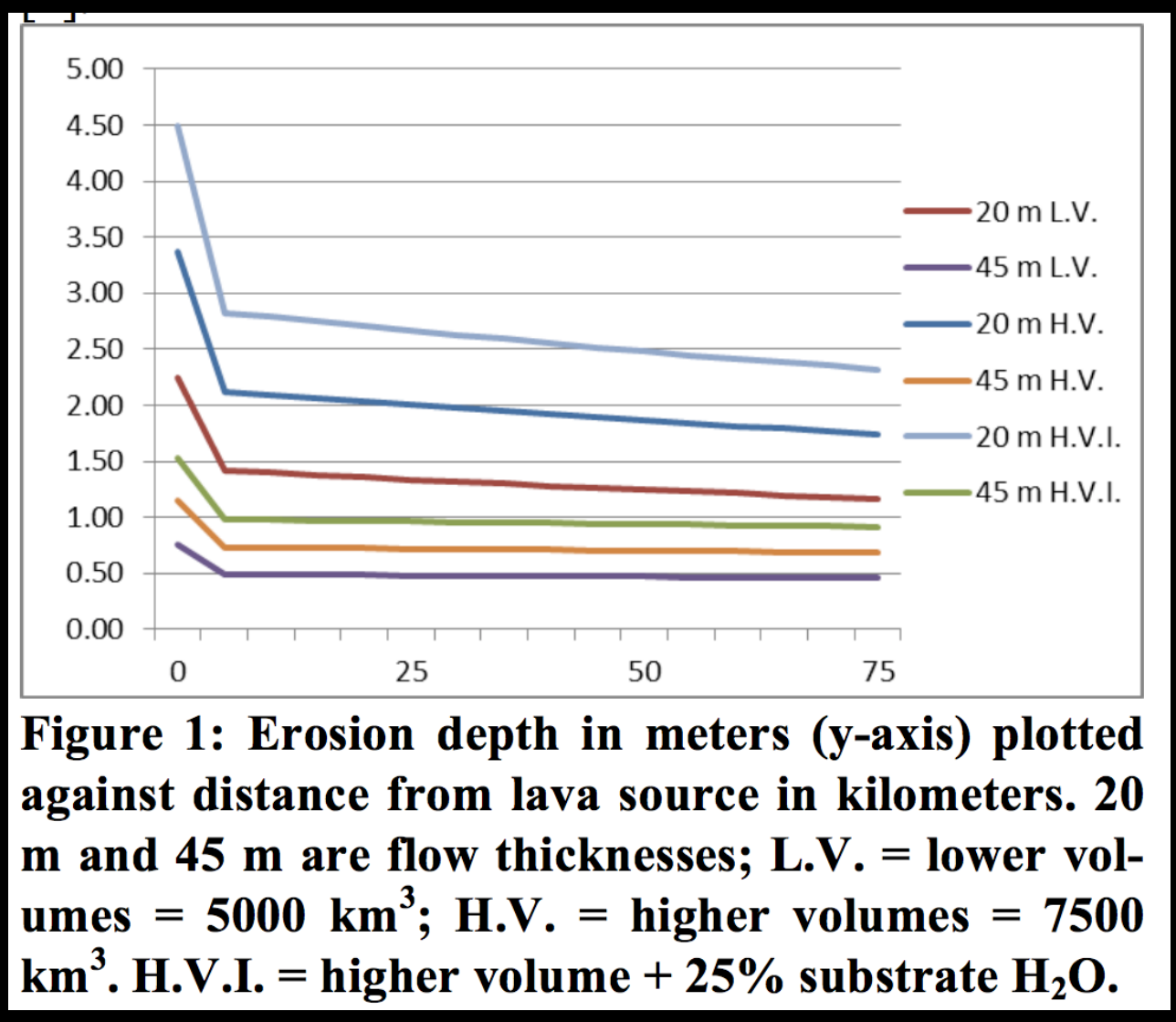

Cataldo et al. 2014 


\section{How to we distinguish fluvial and volcanic channels on Mars?}

- Scale and style of major erosion should be identical

- Can't be eroded by lava if there is no lava - but there can be draping lava

- Key may be secondary features...

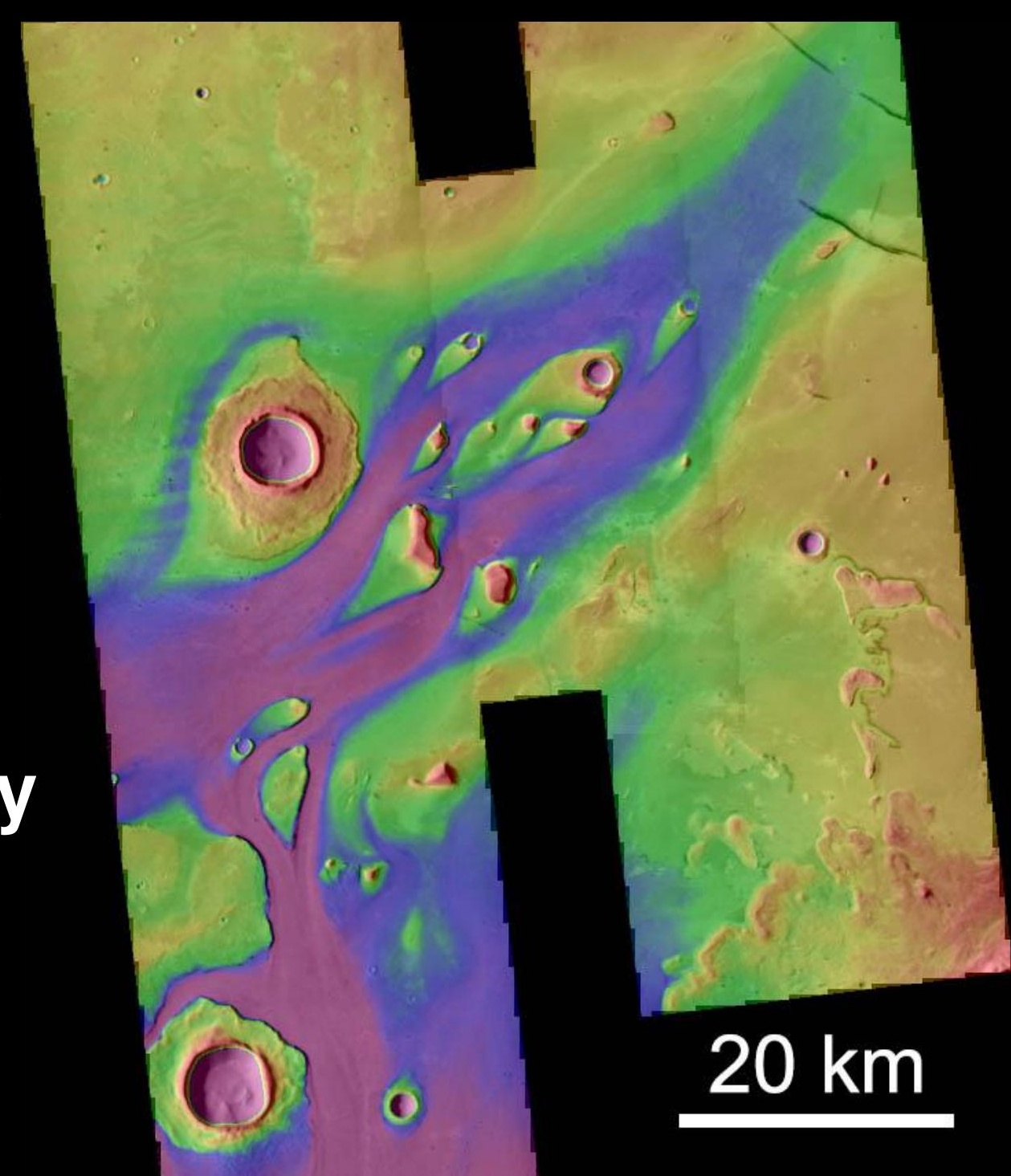




\section{How to we distinguish fluvial and volcanic channels on Mars?}

- Lava should not create m-scale erosion channels

- Lava should not create bedload features (dunes, bars, deltas) because rocks stay in suspension

\section{₹USGS}

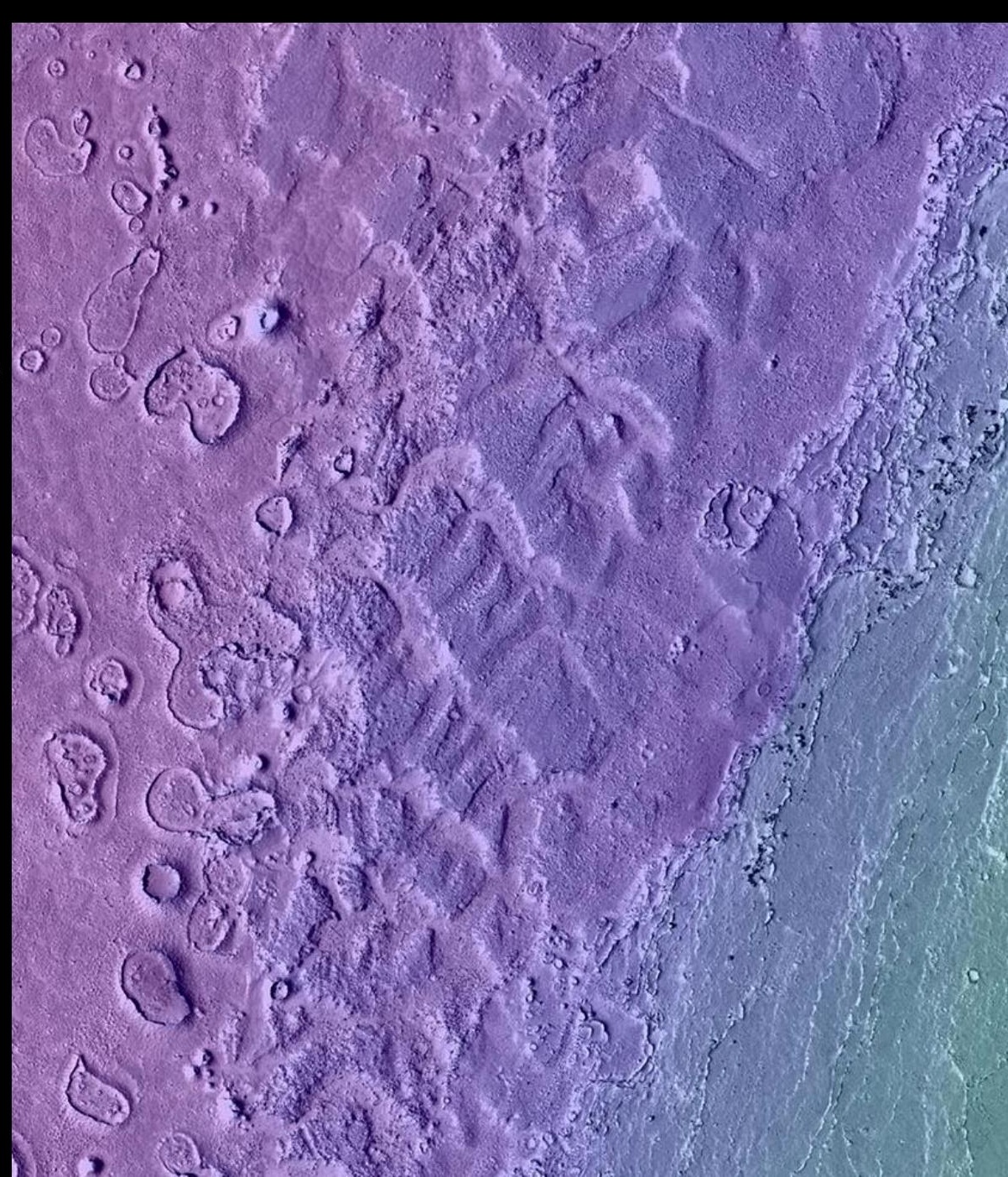




\section{Examples: Kasei Valles}

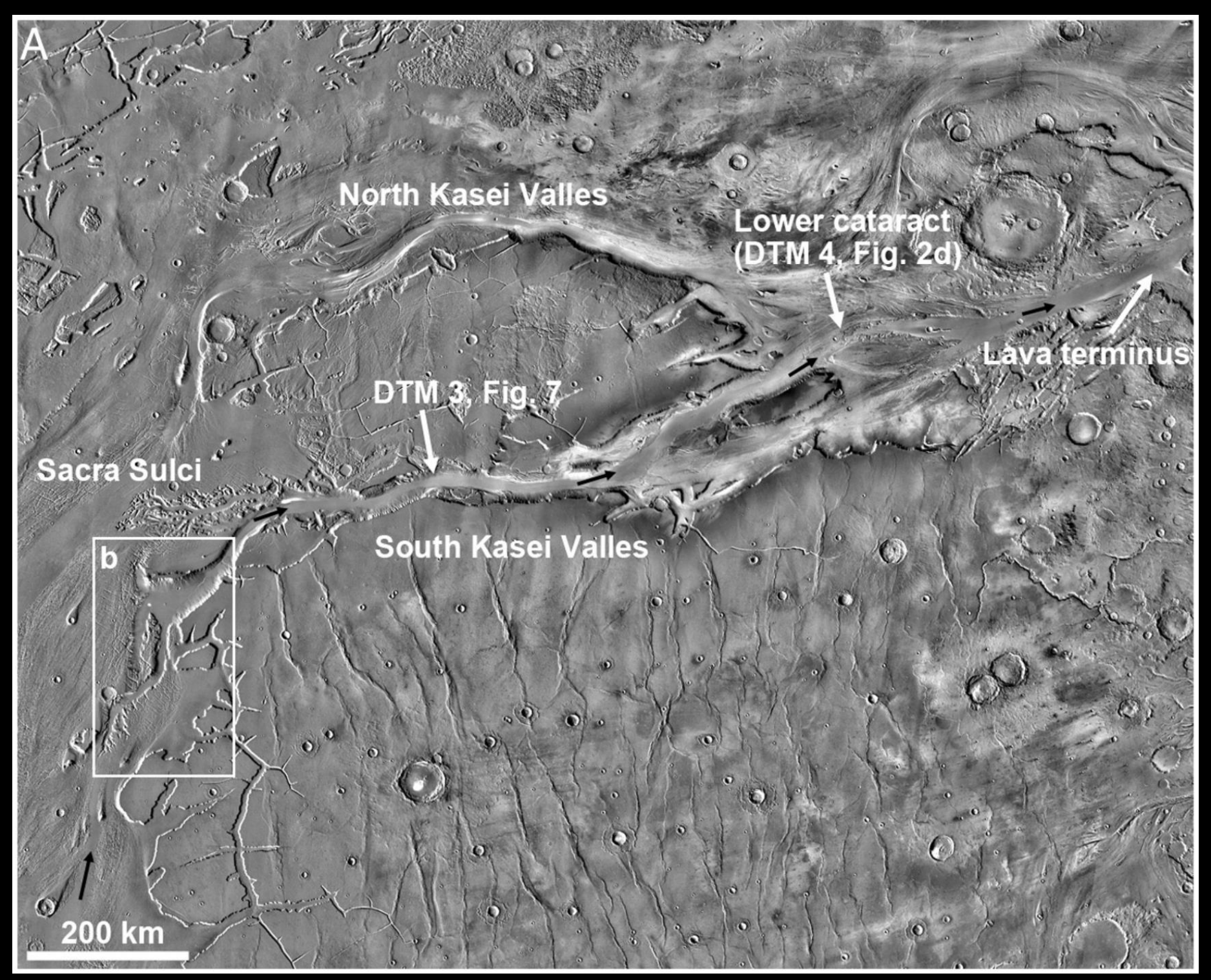




\section{Examples: Kasei Valles}




\section{Examples: Hurwitz et al 2010}

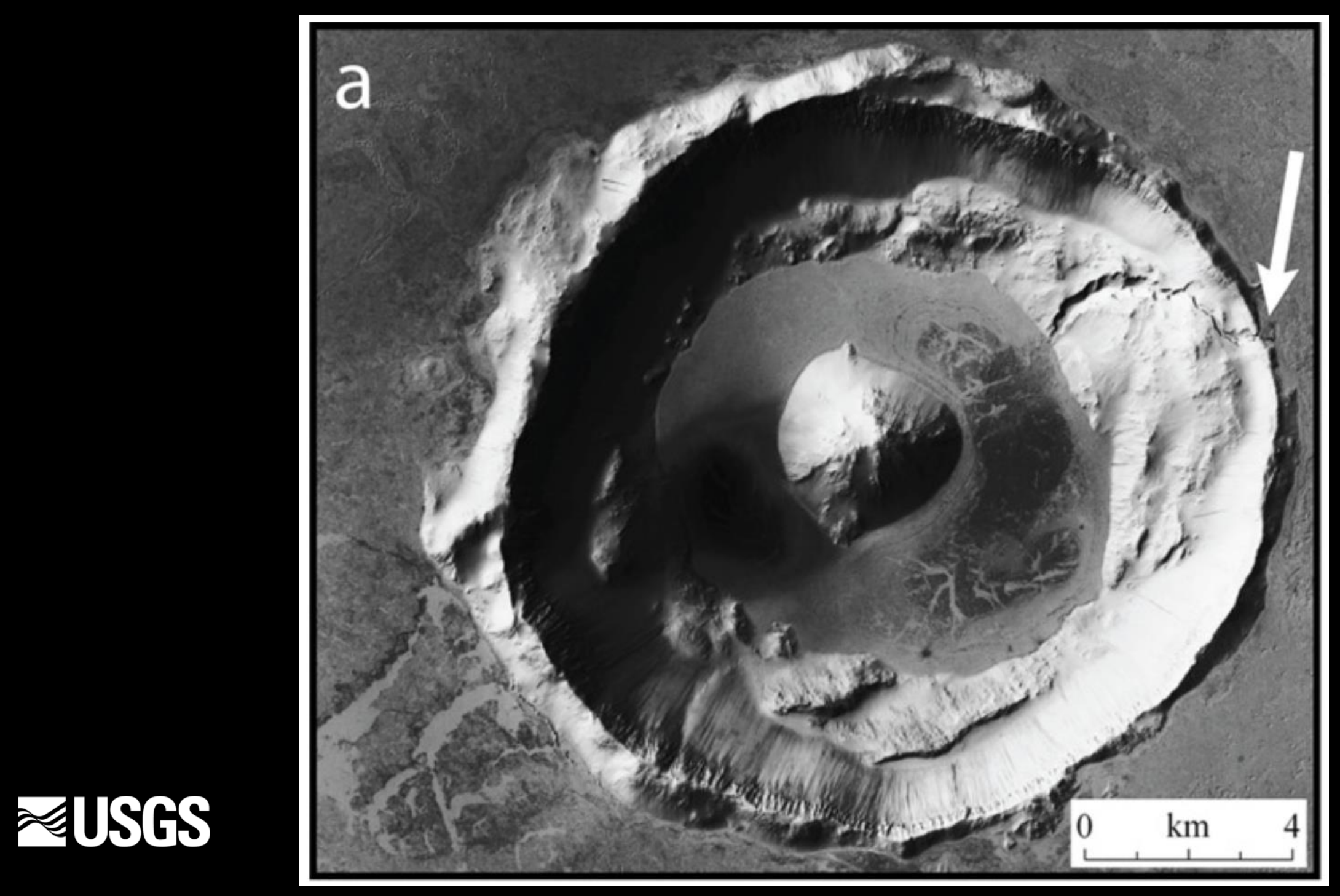




\section{Examples: Hurwitz et al 2010}

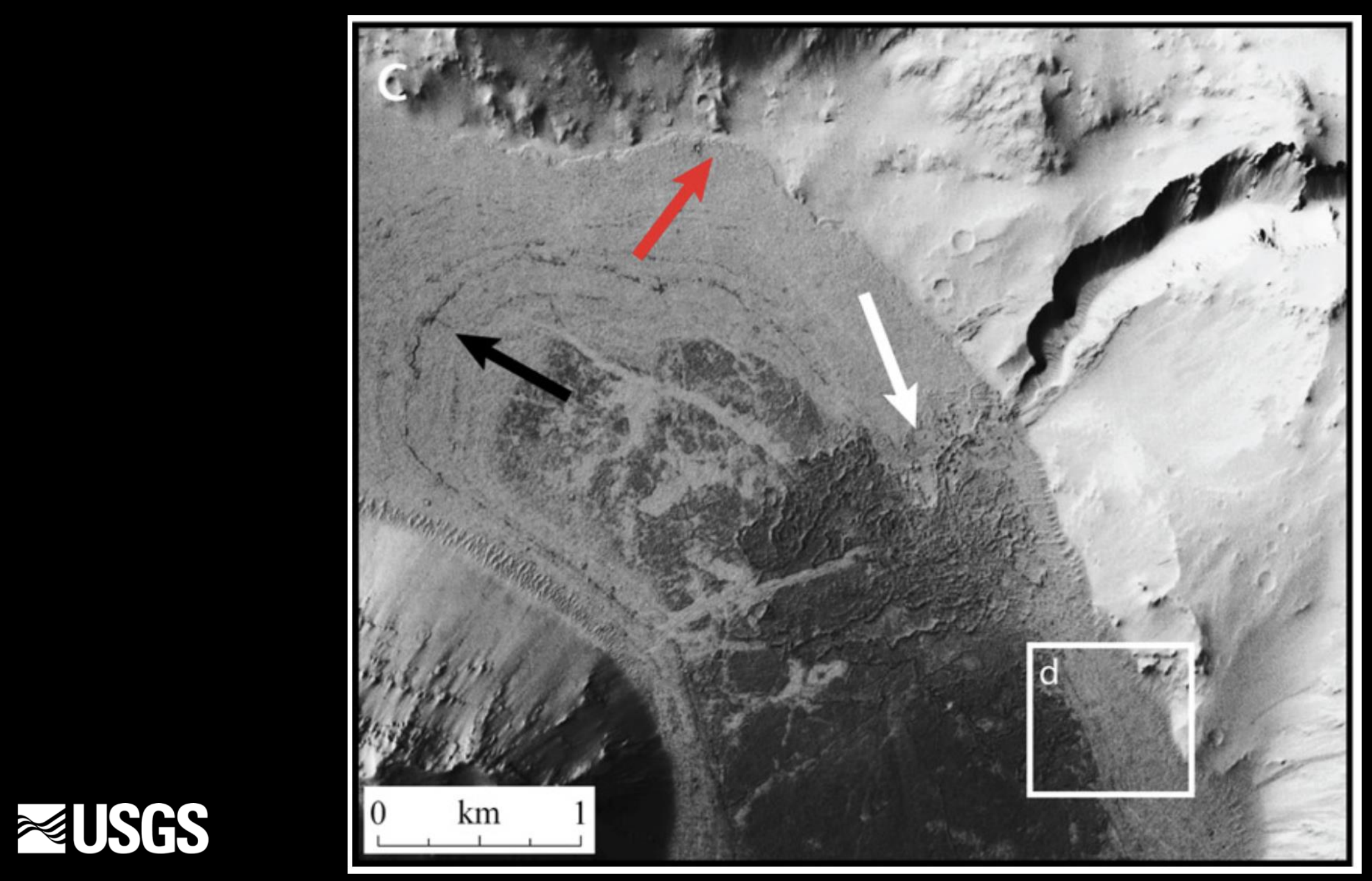




\section{Examples: Rilles}

\section{モUSES}

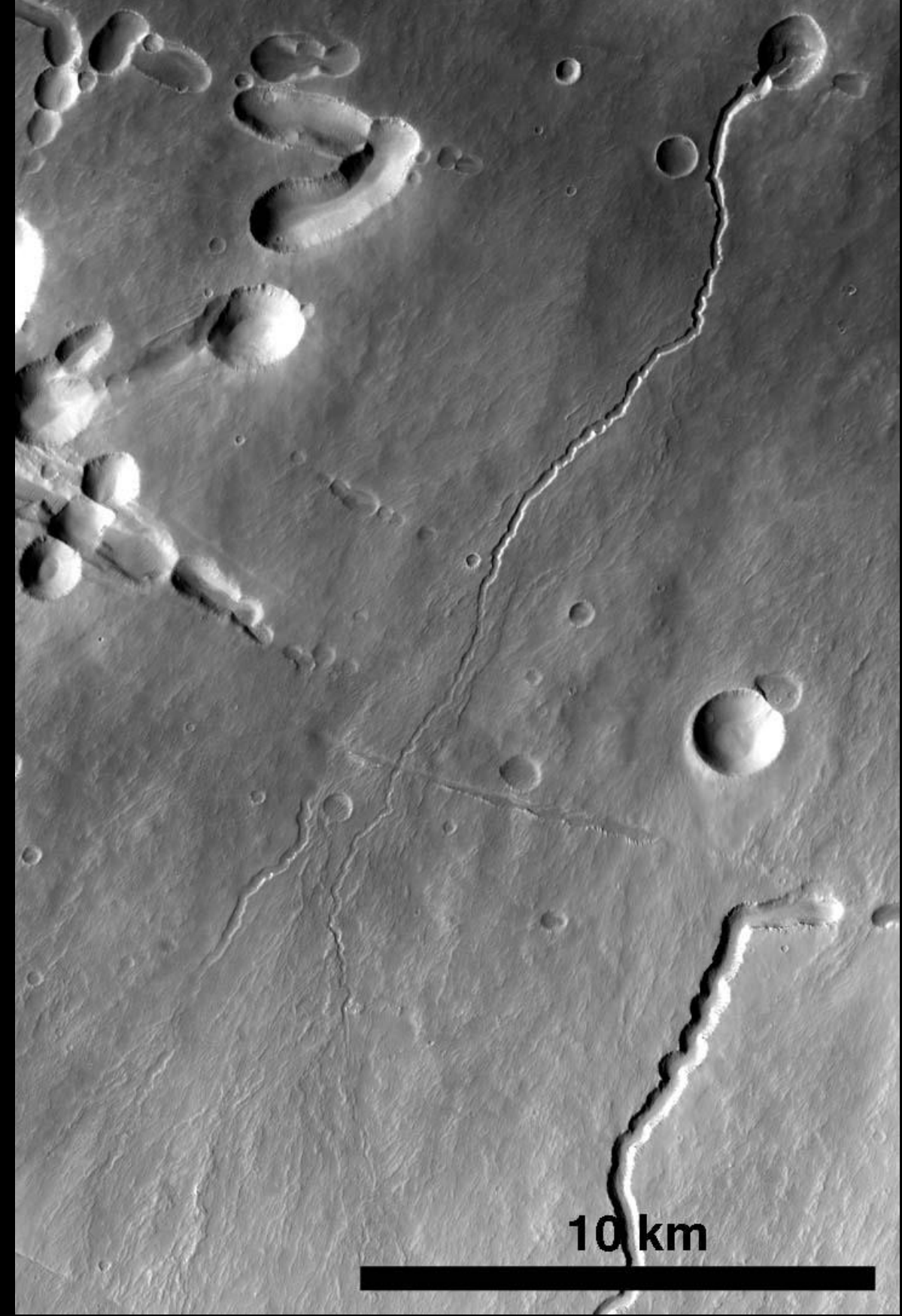




\section{Examples: Athabasca Valles}

\section{モUSES}

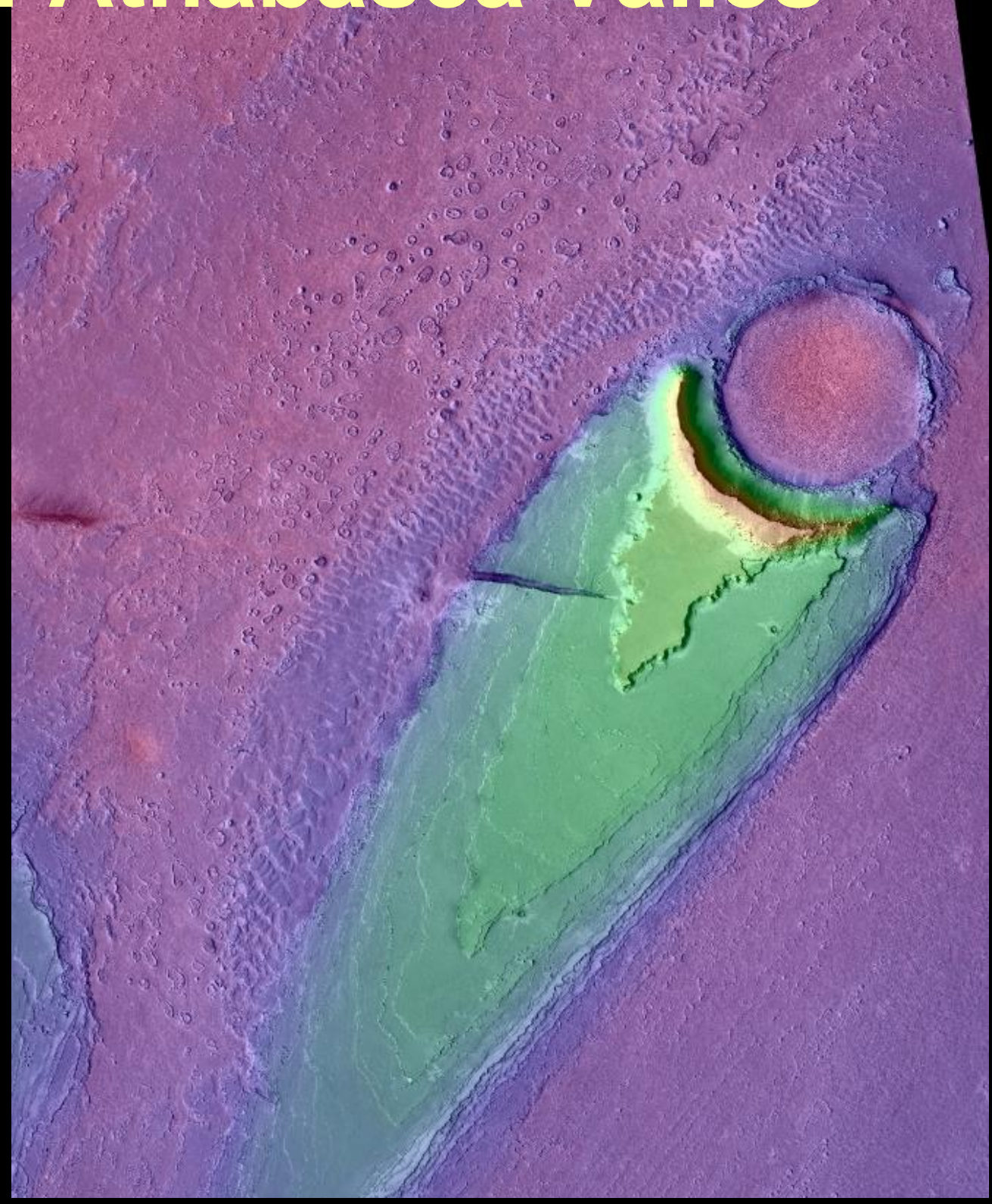




\section{Conclusions}

- Erosion by lava is possible.

- The primary erosion by aqueous and lava floods should be very similar.

- We can identify the erosive fluid when we can observe secondary features.

- There are many good examples of erosion by lava on Mars.

- There are many places that require further study.

\#USGS 